\title{
Rigid polyurethane/expanded vermiculite/ melamine phenylphosphate composite foams with good flame retardant and mechanical properties
}

https://doi.org/10.1515/epoly-2019-0060

Received June 20, 2019; accepted July 18, 2019.

\begin{abstract}
Expanded vermiculite (EV) was introduced into rigid polyurethane (RPU) foam. The incorporation of $10 \mathrm{wt} \% \mathrm{EV}$ into RPU foam increases the compressive strength and the flexural strength by $82 \%$ and by $115 \%$, respectively compared with untreated RPU foam. The LOI of RPU foam containing $20 \mathrm{wt} \% \mathrm{EV}$ is only $19.5 \%$. To further improve the flame retardancy of RPU/EV composite foam, melamine phenylphosphate (MPP) was synthesized and introduced into the RPU/EV composite foam. The RPU/EV composite foam with 15\% MPP (sample RPU/EV/MPP15) has a LOI of $27.5 \%$ and a V0 rating in the vertical UL-94 test. The PHRR and THR of sample RPU/EV/MPP15 decrease by $39 \%$ and $24 \%$, respectively, compared with the ones of untreated RPU/EV composite foam. The compressive strength and flexural strength of RPU/EV/MPP composite foam gradually decrease with the increase in the amount of MPP. TGA results indicated that the addition of MPP further increase the residue char of the RPU/EV composite foam.
\end{abstract}

Keywords: rigid polyurethane foam; expanded vermiculite; melamine phenylphosphate; flame retardancy; mechanical strengths

\section{Introduction}

Rigid polyurethane (RPU) foams are widely used as thermal insulating materials in the field of building and construction because of its excellent mechanical

\footnotetext{
* Corresponding author: Zhengzhou Wang, Department of Polymer Materials, School of Materials Science and Engineering, Tongji University, 4800 Caoan Road, Shanghai 201804, China; Engineering Materials (Tongji University), Ministry of Education, Shanghai 201804, email: zwang@tongji.edu.cn

Zeyu Xia, Department of Polymer Materials, School of Materials Science and Engineering, Tongji University, 4800 Caoan Road, Shanghai 201804, China.
}

properties and low thermal conductivity (1). However, the flammability of polyurethane foams heavily hinders their practical applications, and thus flame retardation of the foams is generally required (2). Flame retardants used for RPU foams consist of two categories: reactive-type and additive-type. Reactive-type flame retardants are mainly organic compounds with flame retardant elements (e.g. $\mathrm{Cl}, \mathrm{Br}, \mathrm{P}, \mathrm{N}$ ) and reactive groups, which can react with polyurethane monomers $(3,4)$. Some halogen-containing flame retardants are efficient for RPU foams, however, their application is restricted in some cases due to the environmental concerns (5). Halogen-free reactive-type flame retardants for RPU foams are mainly diols or polyols containing P, N or P-N groups (6-8). Generally fire resistance of the RPU foams prepared by the halogen-free flame retardant diols or polyols is difficult to meet the stringent requirements in the building and construction industry.

Additive-type halogen-free flame retardants are widely applied in RPU foams because of the simple processing technology and low cost. For example, expandable graphite (EG) is a commonly used additivetype flame retardant for RPU foams. Many researchers have done extensive research work on the use of EG in RPU foams (9-11). It has been found that the factors affecting the flame retardant efficiency of EG in RPU foams include its content, size, expansion ratio, and the density of the foams as well. Although EG is an efficient flame retardant for RPU foams, the incorporation of EG usually led to considerable deterioration of mechanical properties of the foams (12). In addition, phosphorus and nitrogencontaining flame retardants are also widely used additivetype flame retardants in RPU foams (13-15).

Compared with polymer foams, inorganic thermal insulating materials, such as expanded vermiculite (EV), expanded perlite (EP), and foamed concrete have many advantages (e.g. non-combustibility and low cost). However, they also have some disadvantages, i.e. high density and relatively high thermal conductivity. The combination of polymer foams and inorganic thermal insulating materials may be a promising solution 
for thermal insulating applications. The expanded polystyrene (EPS) particles and concrete composite foams have been used in the sector of building and construction. However, the EPS particles are difficultly dispersed evenly in the concrete because of their extreme low density and hydrophobic nature (16). The particles in the concrete will "float", and the mixed slurry is easily layered (17). To solve the problems mentioned above, the surfacial modification of the EPS particles is usually needed to increase their compatibility with the concrete. For example, Johari et al. treated the EPS particles using a hydrophilic coating to improve the affinity between the particles and concrete (18). As for the composite of $\mathrm{PU}$ and inorganic thermal insulating materials, there are very few publications.

In this study, mechanical strengths and flame retardancy of RPU foams containing EV were studied. In order to further improve the flame retardancy of RPU/EV composite foams, a phosphorus- and nitrogen-containing flame retardant, MPP was synthesized and used in the composite foams. The effect of the ratios of MPP and EV on mechanical strengths, flame retardancy, and thermal stability was investigated.

\section{Experimental}

\subsection{Materials}

Phenylphosphoric acid (PPA, AR) was purchased from Sinopharm Chemical Reagent Co., Ltd., China. Melamine (MEL) was a commercial product purchased from Anhui Hongsifang Co., Ltd., China. Polyether polyol (LY-4110, hydroxylvalue: $430 \mathrm{mg} \mathrm{KOH} / \mathrm{g}$ ), and polyaryl polymethylene isocyanate (PM-200, NCO mass percentage 30.5-32\%) were purchased in Jiangsu Lvyuan New Material Co., Ltd., Jiangsu, China. Silicone oil foam stabilizer (SD-103) was purchased from Suzhou Side New Material Technology Co., Ltd. Expanded vermiculite (EV) was purchased from Hebei Tairui Mining Company, China. Triethylenediamine (A33, 33\%) was also purchased from Lvyuan New Materials Co., Jiangsu, China. Dibutyltin laurate (LC) (95\% AR) was purchased from Aladdin Reagent Co., Ltd.

\subsection{Preparation of synthetic melamine phenylphosphate (MPP)}

Phenylphosphoric acid (PPA) (32 g, $0.20 \mathrm{~mol}$ ) was added into a $1000 \mathrm{~mL}$ three-necked flask equipped with a mechanical stir, and then $400 \mathrm{~mL}$ deionized water was added and stirred. After that, melamine (MEL) ( $25.2 \mathrm{~g}, 0.20 \mathrm{~mol}$ ) was added to the PPA solution, and the temperature of the solution was slowly raised to $95^{\circ} \mathrm{C}$. After $4 \mathrm{~h}$ of reaction, the resultant was cooled to room temperature, filtered, and washed several times with deionized water, and finally dried to obtain a white melamine phenylphosphate solid $(89.4 \%$ yield $)$. The synthetic route was shown in Scheme 1.

\subsection{Preparation of pure RPU and RPU composite foams}

For preparation of pure RPU foam, Si-oil, A33 and deionized water were first mixed with polyether polyol in a certain ratio to obtain a uniform mixture. Subsequently, PAPI was quickly added into the above mixture under vigorous stirring for $20 \mathrm{~s}$. Then, the mixture was poured into a mould immediately. Finally, the foam was kept at $60^{\circ} \mathrm{C}$ for $24 \mathrm{~h}$ to complete the curing reaction. As for preparation of the RPU/EV or RPU/EV/MPP composite foams, EV or/and MPP was first added into polyether polyol along with other additives, and other procedures were quite similar to the one of pure RPU foam. The formulations are presented in Table 1.

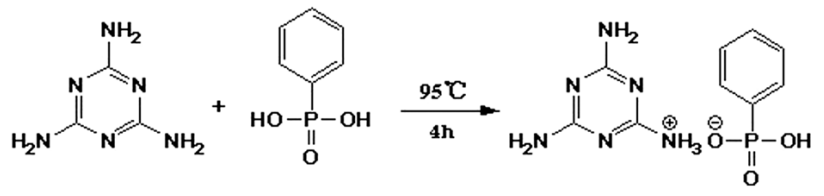

Scheme 1: Synthesis of MPP.

Table 1: Formulations of pure RPU and RPU composite foams.

\begin{tabular}{lccc}
\hline Sample code & RPU (wt\%) & EV (wt \%) & MPP (wt\%) \\
\hline Pure RPU* & 100 & 0 & 0 \\
RPU/EV5 & 95 & 5 & 0 \\
RPU/EV8 & 92 & 8 & 0 \\
RPU/EV10 & 90 & 10 & 0 \\
RPU/EV12 & 88 & 12 & 0 \\
RPU/EV15 & 85 & 15 & 0 \\
RPU/EV20 & 80 & 20 & 0 \\
RPU/EV/MPP0 & 90 & 10 & 0 \\
RPU/EV/MPP5 & 85.5 & 9.5 & 5 \\
RPU/EV/MPP10 & 81 & 9 & 10 \\
RPU/EV/MPP15 & 76.5 & 8.5 & 15 \\
\hline
\end{tabular}

* formulation of pure RPU foam (wt\%): LY4110, 39.76; PM-200, 56.85; A33, 0.40; dibutyltin dilaurate, 0.20; water, 0.80; silicone oil, 0.80; triethylenediamine, 1.19 . 


\subsection{Characterization}

\subsubsection{Cone calorimeter test (CCT)}

Cone calorimeter (CC) tests were carried out according to ISO 5660 standard on a Fire Testing Technology Standard Cone Calorimeter at a heat flux of $35 \mathrm{~kW} / \mathrm{m}^{2}$ with a sample dimension of $100 \times 100 \times 20 \mathrm{~mm}^{3}$.

\subsubsection{Limiting oxygen index ( $\mathrm{LOI})$ and vertical burning tests (UL-94)}

The limiting oxygen index (LOI) was measured with sample dimension of $100 \times 10 \times 10 \mathrm{~mm}^{3}$ according to GB/T 2406-2009 standard. Vertical burning tests (UL-94) (CZF-3, Jiangning Analytical Instrument Factory, China) were performed with sample dimension of $130 \times 13 \times 3 \mathrm{~mm}^{3}$ according to GB/T 2408-2008 standard.

\subsubsection{Thermogravimetric analysis (TG)}

Thermogravimetric analysis was performed under nitrogen atmosphere on a thermo-analyzer instrument (STD Q600, TA Co., USA) to detect thermal decomposition of the samples at a heating rate of $10^{\circ} \mathrm{C} / \mathrm{min}$.

\subsubsection{Compressive strength test}

The compressive strength was measured by a DXLL-5000 universal machine according to GB/T 8812.1-2007 (sample size: $20 \times 20 \times 20 \mathrm{~mm}^{3}$ ), and at least five specimens were tested to obtain an average value.

\subsubsection{Flexural strength test}

The flexural strength was measured by a CMT5105 electronic universal machine according to GB/T 8812.
1-2007 (sample size: $120 \times 25 \times 20 \mathrm{~mm}^{3}$ ), and at least four specimens were tested to obtain an average value.

\subsubsection{Thermal conductivity test}

Thermal conductivity was performed on DHR-II thermal conductivity tester according to GB/T3399-1982 (sample size: $100 \times 100 \times 10 \mathrm{~mm}^{3}$ ).

\section{Results and discussion}

\subsection{Mechanical properties of RPU/EV composite foams}

The effect of EV content on compressive strength and flexural strength of RPU composite foams is shown in Table 2. It can be seen that both compressive strength and flexural strength of RPU composite foams increase first gradually with an increase in EV content. The compressive strength and flexural strength of RPU composite foam reach a maximum at about $10 \% \mathrm{EV}$, an $82 \%$ and $115 \%$ increase, respectively relative to the one of untreated RPU foam. After that loading, the strengths of RPU composite foams decrease gradually, but the values are still higher than those of pure RPU foam. The explanation for above results is as follows. At low loadings, EV, as an inorganic filler, was inserted into the wall of RPU foam structure resulting in an increase in the strengths (19). However, $\mathrm{EV}$ at its high loadings affects the foaming process of RPU foam adversely, producing more defects leading to an obvious decrease in mechanical properties (20).

\subsection{Thermal conductivity of RPU/EV composite foams}

The thermal conductivity of RPU foam is an important factor for its application. Table 2 shows effect of EV

Table 2: The compressive strength, flexural strength, thermal conductivity, LOI and UL-94 results of RPU/EV foams.

\begin{tabular}{|c|c|c|c|c|c|}
\hline Sample code & Compressive strength (MPa) & Flexural strength (MPa) & Thermal conductivity $(\mathrm{W} /(\mathrm{m} \cdot \mathrm{K}))$ & LOI (\%) & UL-94 rating \\
\hline Pure RPU* & 0.26 & 0.137 & 0.0235 & 18 & Fail \\
\hline RPU/EV5 & 0.36 & 0.205 & 0.0243 & 18.5 & Fail \\
\hline RPU/EV8 & 0.47 & 0.280 & 0.0245 & 19 & Fail \\
\hline RPU/EV10 & 0.51 & 0.295 & 0.0246 & 19 & Fail \\
\hline RPU/EV12 & 0.39 & 0.245 & 0.0253 & 19 & Fail \\
\hline RPU/EV15 & 0.37 & 0.225 & 0.0257 & 19.5 & Fail \\
\hline RPU/EV20 & 0.34 & 0.165 & 0.0280 & 19.5 & Fail \\
\hline
\end{tabular}


content on thermal conductivity of RPU/EV composite foams. The thermal conductivity of pure RPU foam was $0.0235 \mathrm{~W} /(\mathrm{m} \cdot \mathrm{K})$. The thermal conductivity of RPU/EV composite foams increased with an increase in EV content. For example, the thermal conductivity of RPU composite foam containing $10 \% \mathrm{EV}$ was $0.0246 \mathrm{~W} /(\mathrm{m} \cdot \mathrm{K})$, which was $4.7 \%$ higher than that of pure RPU foam. It was probably because that the addition of EV decreased the size of the cells in the RPU foam and formed some agglomeration in the matrix, providing access to heat transfer, thus facilitating heat transfer $(21,22)$.

\subsection{Flame retardant properties of RPU/EV composite foams}

\subsubsection{LOI and UL-94 rating}

The limiting oxygen index (LOI) and UL-94 burning tests were used to assess flammability performance of RPU foams. As shown in Table 2, the LOI value of pure RPU foam is $18.0 \%$, and the LOI values of RPU/EV composite foams increase slightly. For example, the LOI of RPU/EV composite foam containing $20 \% \mathrm{EV}$ is only $19.5 \%$. The UL 94 test results indicate that both pure RPU and $\mathrm{RPU} / \mathrm{EV}$ composite foams have no ratings at all. Above results illustrate that EV has low flame retardant efficiency in RPU foam.

\subsubsection{Cone calorimeter study}

Cone calorimeter is usually used to study the flammability characteristics of polymer materials, and its results can be applied to evaluate fire safety behavior of the materials in a real fire condition (23). Figure 1 shows heat release rate (HRR) and total heat release (THR) curves of pure RPU and RPU/EV composite foams, respectively. Some cone calorimeter test results are given in Table 3. It can be seen that the incorporation of EV leads to a gradual decrease in the peak heat release rate (PHRR) of RPU foam. The PHRR value of RPU/EV composite foams (samples RPU/EV5, RPU/EV10, and RPU/EV15) at 5\%, 10\% and 15\% EV, decrease $22 \%, 27 \%$ and $36 \%$, respectively compared with that of pure RPU foam. The total heat release (THR) of samples RPU/EV5, RPU/EV10, and RPU/EV15 are 23\%, $28 \%$ and $38 \%$, respectively lower than that of pure RPU foam. Moreover, the reduction of total smoke release (TSR) of samples RPU/EV5, RPU/EV10, and RPU/EV15 are $19 \%, 25 \%$ and $27 \%$, respectively compared with pure RPU foam, as shown in Table 3. The decrease of PHRR, THR and TSR of RPU/EV composite foams may be because EV as a porous material, can absorb the heat and smoke produced during the combustion of the composite foams $(24,25)$, and may be due to the formation of more and denser char with an increase in the EV content, as shown in Figure 2.

Table 3: Cone calorimetry test results of RPU/EV composite foams.

\begin{tabular}{lccc}
\hline Sample code & PHRR $^{\mathrm{a}}\left(\mathbf{k W} / \mathrm{m}^{2}\right)$ & THR $\left.^{\mathrm{b}}(\mathbf{M}) / \mathrm{m}^{2}\right)$ & $\mathrm{TSR}^{\mathrm{c}}\left(\mathrm{m}^{2} / \mathrm{m}^{2}\right)$ \\
\hline Pure RPU & 344 & 25.8 & 535 \\
RPU/EV5 & 267 & 19.8 & 433 \\
RPU/EV10 & 252 & 18.6 & 402 \\
RPU/EV15 & 220 & 16.0 & 390 \\
\hline
\end{tabular}

a PHRR - peah heat release rate; ${ }^{\mathrm{b}} \mathrm{THR}$ - total heat release;

c TSR - total smoke release.
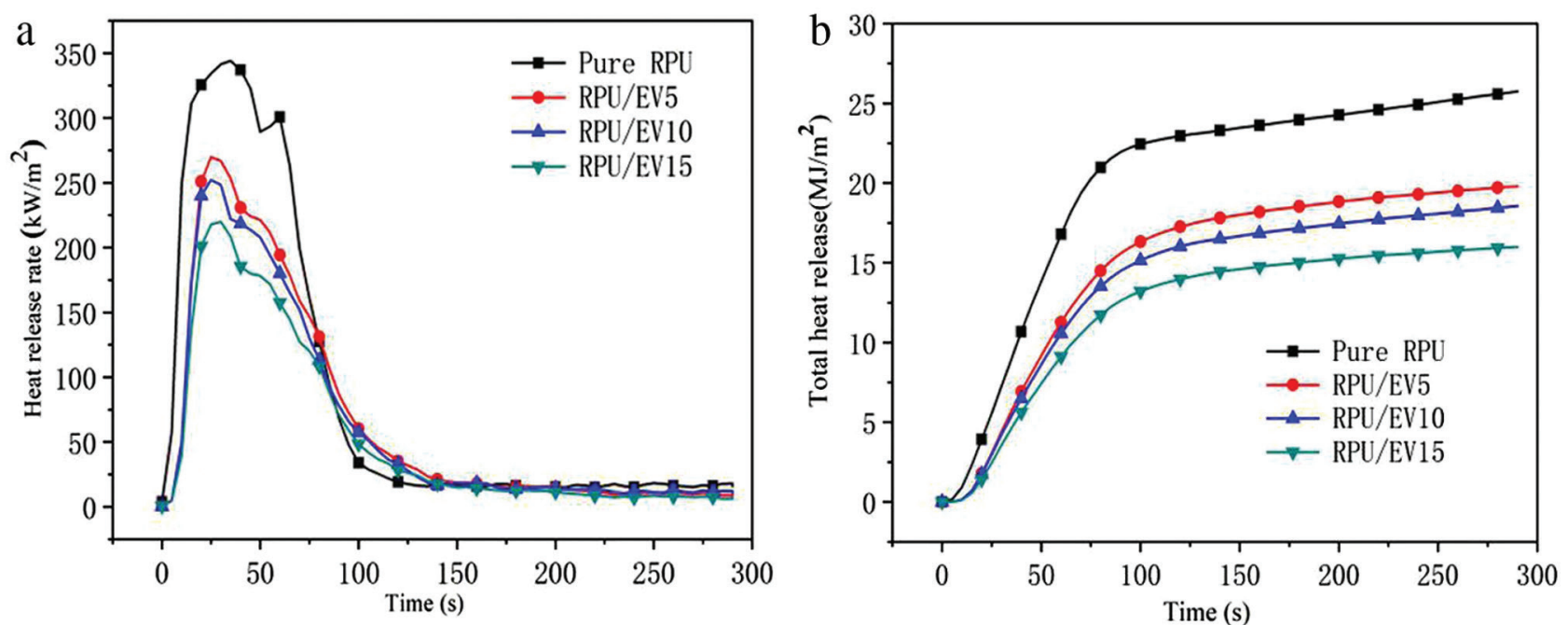

Figure 1: (a) HRR curves of RPU/EV foams; (b) THR curves of RPU/EV foams. 


\subsection{Foam structure of RPU/EV composite foams}

The foam structure of RPU foams containing EV was observed by SEM (Figure 3). It is seen that the incorporation of EV into RPU foam leads to a decrease in the cell size. RPU foam with $5 \mathrm{wt} \%$ or $10 \mathrm{wt} \% \mathrm{EV}$ shows the smaller average cell diameter, with denser and more regular cell distributions, compared to untreated RPU foam. This phenomenon is explained by the fact that EV acting as an inorganic filler located on cell wall restricts the increase of cell sizes $(26,27)$. However, the incorporation of $15 \mathrm{wt} \% \mathrm{EV}$ into RPU foam results in a slight increase in the average cell sizes, which may be due to the agglomeration of $\mathrm{EV}$ at high loadings. Moreover, at 15\% EV content, the distribution of the cells of sample RPU/EV15 becomes less uniform. Although the average cell size of sample RPU/EV15 is higher than the one of sample PU/EV 10, its cell-size distribution is still more uniform than that of untreated RPU foam.
The above results can explain the change of mechanical strengths of RPU composite foams with EV.

\subsection{Flame retardant properties of RPU/EV/MPP composite foams}

\subsubsection{Limiting oxygen index (LOI) and UL-94 rating}

The incorporation of EV can lead to a great increase in mechanical strengths and a decrease in PHRR, THR and TSR of RPU foam, however, flame retardancy of RPU/EV composite foams is not satisfactory in terms of LOI and the UL 94 rating. In order to improve the flame retardancy of RPU/EV composite foams, a flame retardant, i.e. melamine phenylphosphate (MPP), was further added into the composite foams. As can be seen in Table 4, the LOI of the RPU/EV foam with $0 \%$ MPP is $19 \%$, and the LOI values of RPU/EV/MPP foams increase gradually with
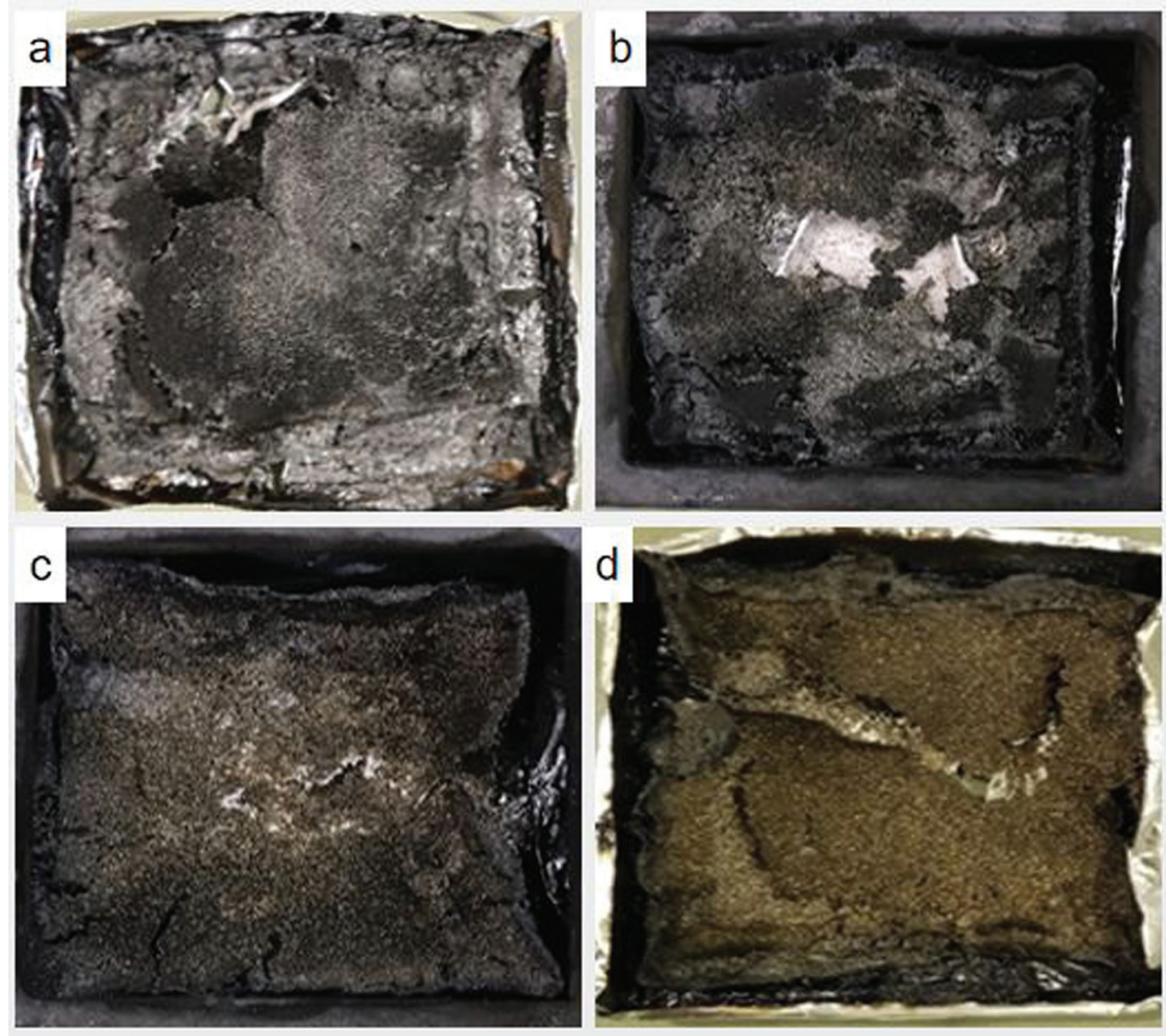

Figure 2: Digital photos for the residues after CCT: (a) pure RPU, (b) RPU/EV5, (c) RPU/EV10, (d) RPU/EV15. 


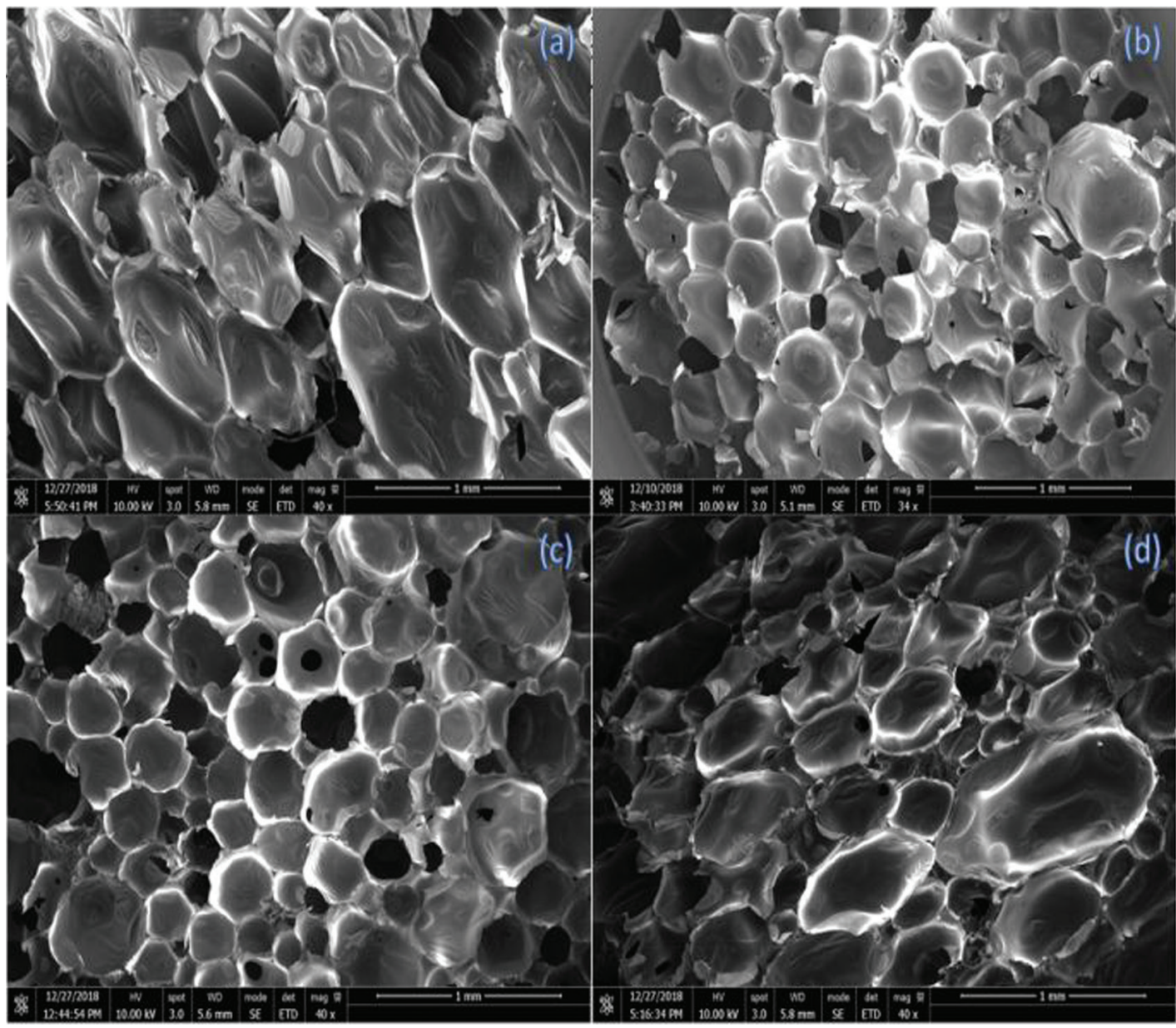

Figure 3: SEM images of RPU/EV foams: (a) pure RPU, (b) RPU/EV5, (c) RPU/EV10, (d) RPU/EV15.

Table 4: LOI, UL-94 rating, mechanical strengths and thermal conductivity of RPU composite foams.

\begin{tabular}{lccccc}
\hline Sample code & LOI (\%) & UL-94 rating & Compressive strength $(\mathbf{M P a})$ & Flexural strength $(\mathrm{MPa})$ & Thermal conductivity $(\mathbf{W} /(\mathrm{m} \cdot \mathrm{K}))$ \\
\hline RPU/EV/MPP0 & 19.0 & Fail & 0.51 & 0.295 & 0.0246 \\
RPU/EV/MPP5 & 22.0 & Fail & 0.48 & 0.270 & 0.0246 \\
RPU/EV/MPP10 & 24.0 & Fail & 0.41 & 0.187 & 0.0256 \\
RPU/EV/MPP15 & 27.5 & V-0 & 0.28 & 0.136 & 0.0264 \\
\hline
\end{tabular}

an increase in the MPP content. When the MPP content is $15 \mathrm{wt} \%$, the LOI value of the RPU/EV/MPP composite foam (sample RPU/EV/MPP15) increases to $27.5 \%$ and the composite foam reaches the UL $94 \mathrm{~V} 0$ rating. The results illustrate that a desired flame retardancy of RPU foam can be achieved with an appropriate addition of EV and MPP.

\subsubsection{Cone calorimeter study}

Figure 4 shows PHRR and THR curves of RPU/EV/MPP composite foams, and some cone calorimeter data are listed in Table 5. It can be seen that the incorporation of MPP into RPU/EV composite foams leads to a further decrease in PHRR and THR. PHRR and THR of RPU/EV/MPP composite foams decrease with an increase of the MPP content. PHRR and THR values of RPU/EV/MPP composite foams containing $15 \%$ MPP are reduced by $39 \%$ and $24 \%$, respectively compared with the ones of RPU/EV composite foam without MPP. The reason for the decrease in PHRR and THR of the RPU/EV composite foams with MPP is possibly because the decomposition of MPP not only releases noncombustible gases $\left(\mathrm{H}_{2} \mathrm{O}, \mathrm{N}_{2}\right.$, and $\left.\mathrm{NH}_{3}\right)$ during the combustion, which dilute oxygen and combustible gases in the gaseous phase, but also forms phosphorus-containing acids, which catalyze dehydration of polyols from RPU depolymerization 

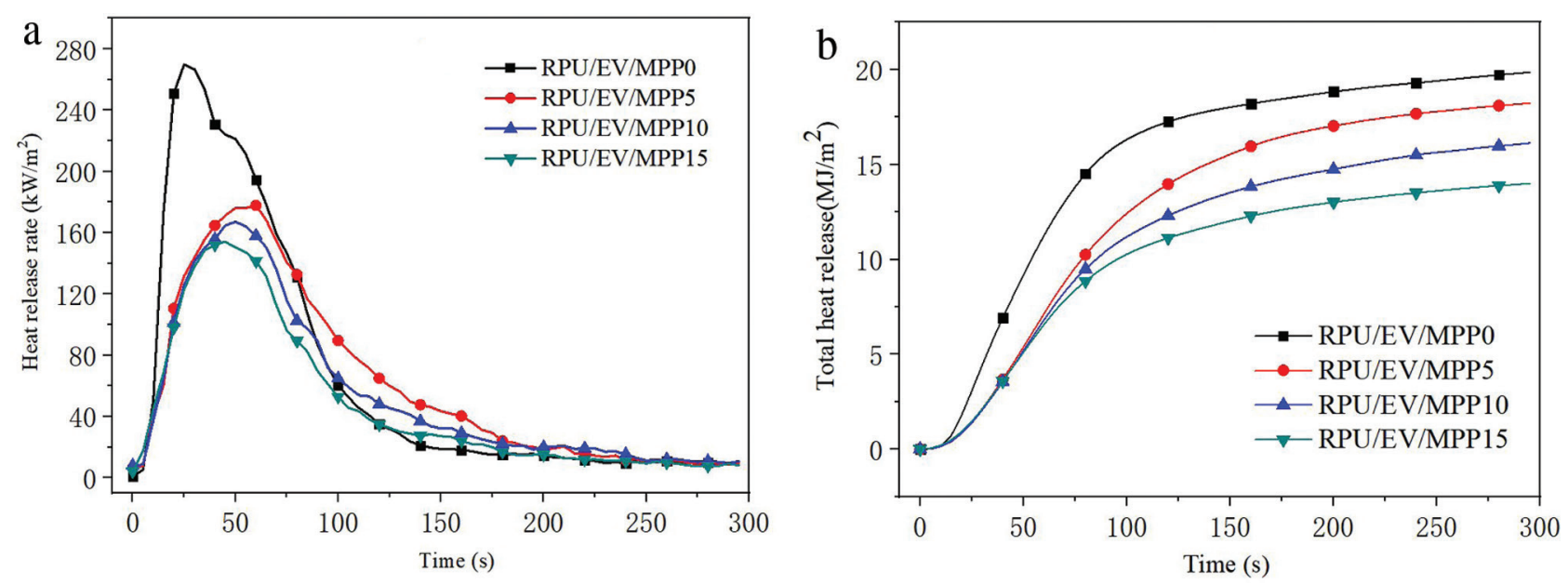

Figure 4: (a) HRR curves of RPU/EV/MPP foams; (b) THR curves of RPU/EV/MPP foams.

Table 5: Cone calorimeter test results of RPU/EV/MPP composite foams.

\begin{tabular}{lccc}
\hline Sample code & PHRR $\left(\mathrm{kW} / \mathrm{m}^{2}\right)$ & THR $\left(\mathrm{MJ} / \mathrm{m}^{2}\right)$ & $\mathrm{TSR}\left(\mathrm{m}^{2} / \mathrm{m}^{2}\right)$ \\
\hline RPU/EV/MPP0 & 252 & 18.6 & 402 \\
RPU/EV/MPP5 & 178 & 18.2 & 579 \\
RPU/EV/MPP10 & 167 & 16.1 & 614 \\
RPU/EV/MPP15 & 154 & 14.0 & 675 \\
\hline
\end{tabular}

and promote formation of carbonaceous char. Moreover $\mathrm{EV}$, as a porous material, can absorb a certain amount of high temperature gases during combustion, which not only reduces PHRR, but also reduces smoke emission. Besides, the combination of MPP and EV may improve the char yield and char quality, as shown in Figure 5, preventing combustible gases from diffusing to a flame zone and providing good shielding effect to unburned substrate from heat and oxygen (28-31). Therefore, the addition of EV and MPP in a proper proportion can significantly improve the flame retardancy of the RPU foam. Figure 5 shows the residue chars of RPU/EV/MPP composite foams after CCT. It can be seen that the higher the MPP content in the composite foams, the more the char left after the combustion. Although total smoke release (TSR) of RPU/EV/MPP composite foams increases gradually with an increase in the MPP content, the value is still comparable with the value of pure RPU foam $\left(535 \mathrm{~m}^{2} / \mathrm{m}^{2}\right)$.

\subsection{Mechanical properties of RPU/EV/MPP composite foams}

The effect of MPP content on the compressive strength and flexural strength of RPU/EV/MPP composite foams was studied. Table 4 shows that the compressive strength and flexural strength of RPU/EV/MPP foam gradually decrease with the increase of MPP content, but the mechanical strengths of all samples were better than those of untreated RPU foam. For example, when the MPP content is $10 \mathrm{wt} \%$, the compressive strength and flexural strength of RPU/EV/MPP foam are $0.41 \mathrm{MPa}$ and $0.187 \mathrm{MPa}$, an increase of $46.4 \%$ and $32.1 \%$, respectively, compared with that of untreated RPU foam. The decrease in the mechanical strengths of RPU/EV/MPP composite foams may be due to the poor compatibility between MPP and $\mathrm{PU}$, resulting in more defects in the foaming process (32).

\subsection{Thermal conductivity of RPU/EV/MPP composite foams}

It can be seen from Table 4 that the addition of MPP can also lead to a slight increase in the thermal conductivity of the RPU/EV/MPP composite foams. In general, the thermal conductivity of RPU foam depends on the cell size, cell orientation, ratio of close to open cell and the thermal conductivity of the trapped gases in the cell as well as on the filling materials $(16,21)$. The thermal conductivity of $\mathrm{RPU} / \mathrm{EV} / \mathrm{MPP}$ composite foams increases from 0.0247 to $0.0266 \mathrm{~W} /(\mathrm{m} \cdot \mathrm{K})$ with the MPP content increases from $0 \mathrm{wt} \%$ to $15 \mathrm{wt} \%$.

\subsection{Foam structure of RPU/EV/MPP composite foams}

Figure 6 shows the SEM images of foam structure of $\mathrm{RPU} / \mathrm{EV} / \mathrm{MPP}$ composite foams. It can be seen that the cell size of the pure RPUF was large and there were many 

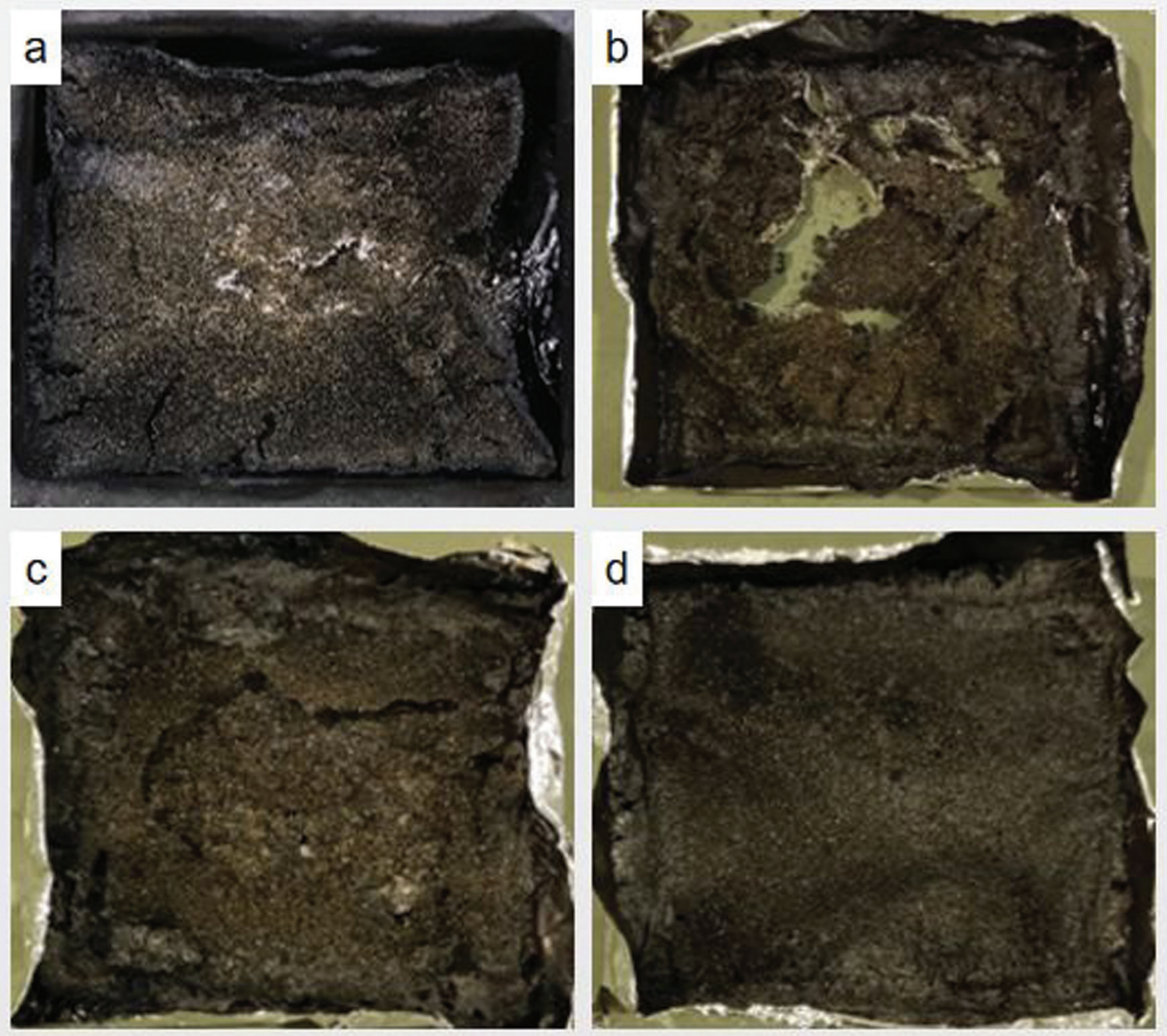

Figure 5: Digital photographs for the residues after CCT: (a) RPU/EV/MPP0, (b) RPU/EV/MPP5, (c) RPU/EV/MPP10, (d) RPU/EV/MPP15.

defects in the cell wall. When the content of MPP was 5\% (sample PU/EV/MPP5), the cell size and defect decrease obviously with a more regular cell distribution. This may be because a small amount of MPP addition together with EV restricted the growth of cell size and enhanced the integrity of cell $(33,34)$. However, with the increasing content of MPP added, MPP will form a certain degree of agglomeration on the cell wall, which led to a larger cell size.

\subsection{Thermogravimetric analysis of RPU/EV and RPU/EV/MPP composite foams}

Figure 7 shows TG and DTG curves of RPU composite foams and some data are listed in Table 6. It can be seen that $\mathrm{EV}$ has nearly no weight loss below $500^{\circ} \mathrm{C}$ and its weight percent at $800^{\circ} \mathrm{C}$ is as high as $96.8 \%$. The degradation process of untreated RPU was divided into two steps. The first step of degradation between $200^{\circ} \mathrm{C}$ and $440^{\circ} \mathrm{C}$ is attributed to the depolymerization reaction, releasing small monomer precursors, such as polyol and isocyanates, and the second step occurring from $440^{\circ} \mathrm{C}$ to $700^{\circ} \mathrm{C}$ is due to the degradation of substituted urea, which was produced from the reaction of carbodiimide with alcohol or water vapor (35). EV incorporation into the foam appeared not to affect these degradation steps, but increased $\mathrm{T}-5 \%$ from $257^{\circ} \mathrm{C}$ (Pure RPU) to $270^{\circ} \mathrm{C}$ (Table 6) which indicated that EV delayed the thermal decomposition of the foam. EV decreased the weight loss rate of RPU/EV foams compared with untreated RPU foam. For example, the char residue at $800^{\circ} \mathrm{C}$ from sample RPU/EV10 foam was $15.37 \%$, which was higher than that $(6.16 \%)$ of untreated RPU foam, indicating that the RPU/EV foam was more stable than untreated RPU foam at high temperatures. These results can be explained by the high thermal stability of EV (36-39). As for RPU/EV/MPP foam, its T-5\% was decreased compared with the one of RPU/EV foam, which was contributed to the early thermal 


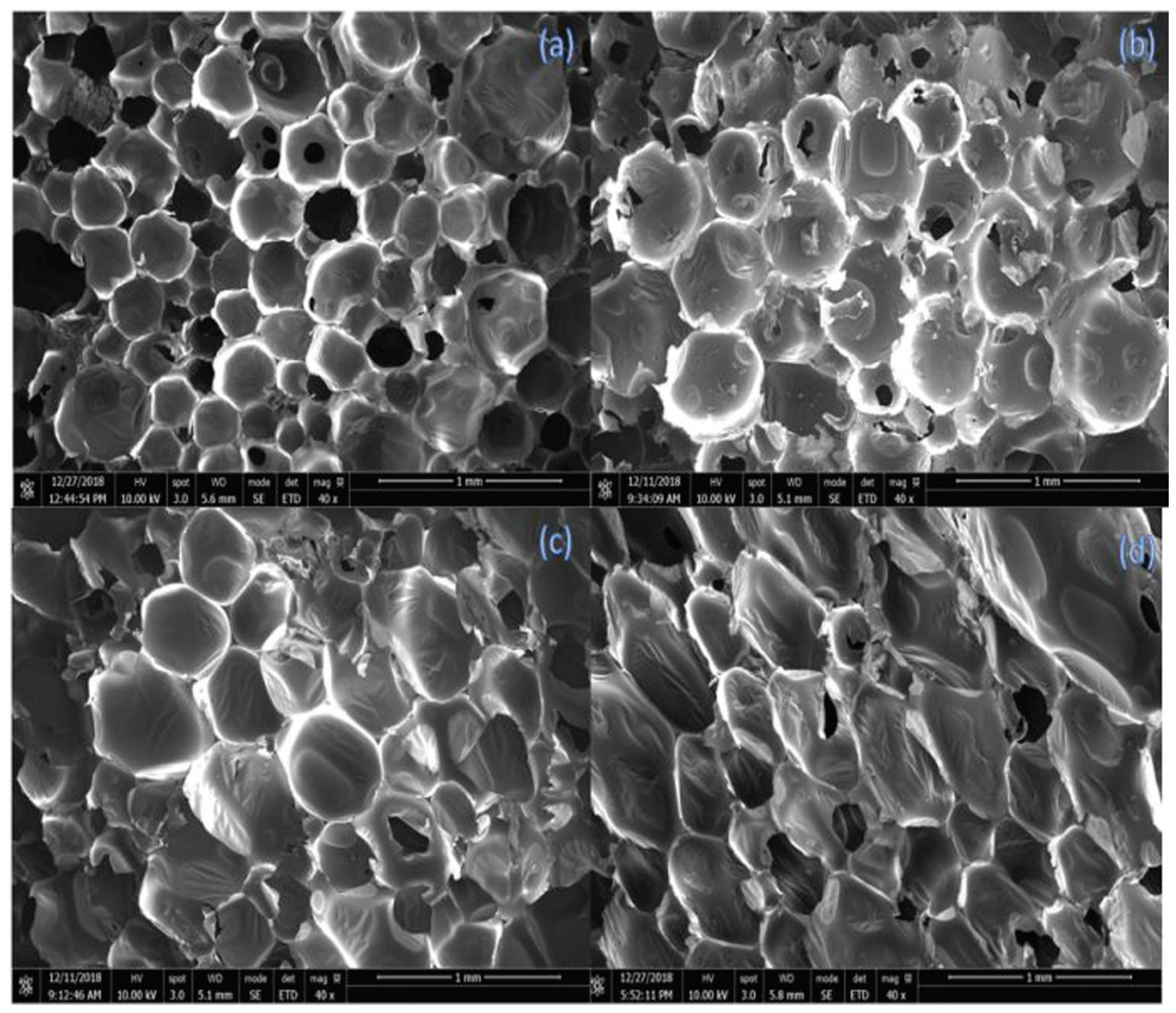

Figure 6: SEM images of RPU/EV/MPP foams: (a) RPU/EV/MPP0, (b) RPU/EV/MPP5, (c) RPU/EV/MPP10, (d) RPU/EV/MPP15.
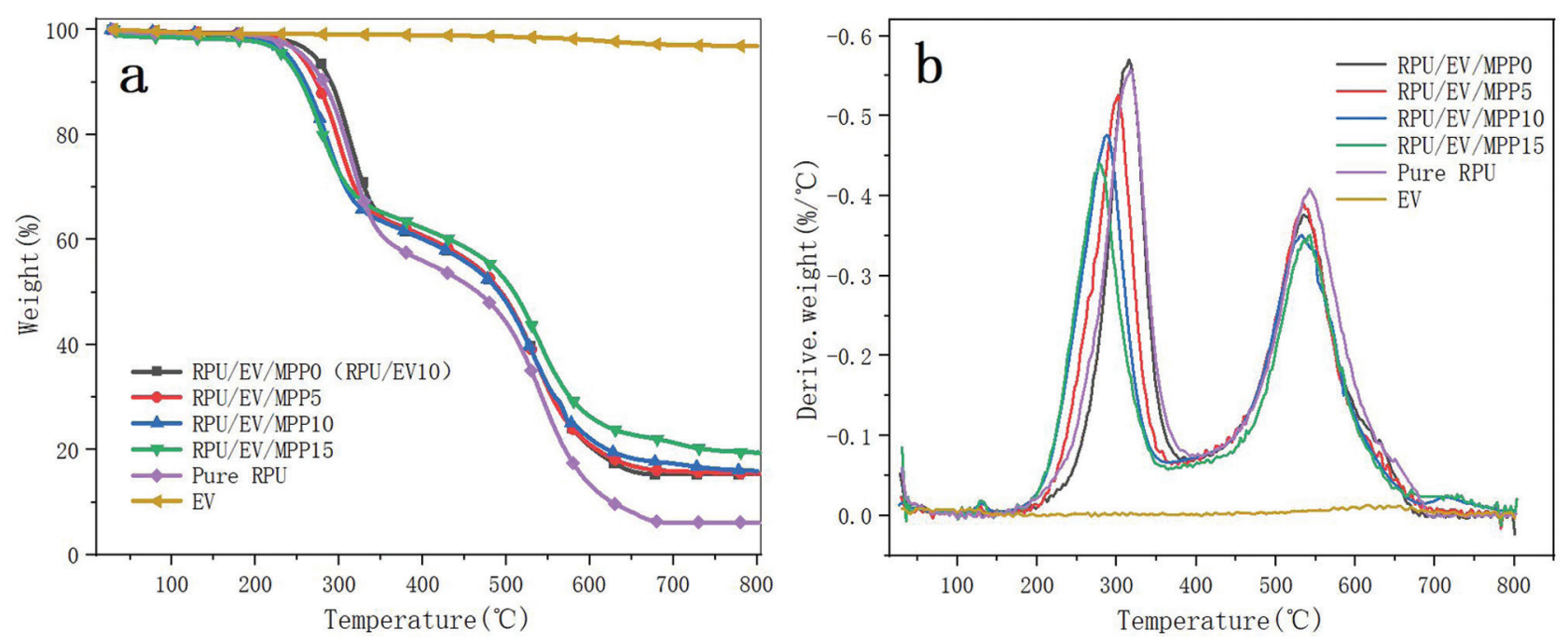

Figure 7: TG (a) and DTG (b) curves of RPU composite foams.

decomposition of MPP. But the incorporation of MPP led to a higher T-50\%, which means that the RPU/EV/MPP foam formed denser carbon layer, protecting the unburned matrix and slowing the rate of weight loss. Besides, it was concluded from DTG curves that MPP decreased the weight loss rate of RPU foam/EV foams compared with 
Table 6: T-5\%, T-50\% and residue of RPU composite foams in TG test.

\begin{tabular}{lccc}
\hline Sample code & T-5\% $\left.{ }^{\circ}{ }^{\circ} \mathrm{C}\right)$ & T- $50 \%^{\mathrm{b}}\left({ }^{\circ} \mathrm{C}\right)$ & Residue $^{c}(\%)$ \\
\hline Pure RPU & 257 & 465 & 6.16 \\
RPU/EV/MPP0 & 270 & 490 & 15.37 \\
(RPU/EV10) & & & \\
RPU/EV/MPP5 & 254 & 495 & 15.46 \\
RPU/EV/MPP10 & 239 & 497 & 15.95 \\
RPU/EV/MPP15 & 233 & 510 & 19.42 \\
\hline
\end{tabular}

${ }^{\text {a }} \mathrm{T}-5 \%$, temperature at $5 \%$ weight loss; ${ }^{\mathrm{b}} \mathrm{T}-50 \%$ temperature at $50 \%$ weight loss; ${ }^{\mathrm{c}}$ residue, residual weight at $800^{\circ} \mathrm{C}$.

RPU/EV foam. The residue of RPU/EV/MPP foam at $800^{\circ} \mathrm{C}$ had a slight increase with the increase of MPP content. The TG curves showed that the residual char ratio of sample $\mathrm{EPU} / \mathrm{EV} / \mathrm{MPPO}$ was $15.4 \%$ at $800^{\circ} \mathrm{C}$ while the residual char ratio of RPU/EV/MPP15 was 19.4\%. In addition, the initial decomposition temperature of RPU/EV/MPP foam decreased with the addition of MPP. The char residues at $800^{\circ} \mathrm{C}$ from samples RPU/EV/MPP5, RPU/EV/MPP10, and RPU/EV/MPP15 were all higher than that of sample RPU/EV/MPP0, which meant that the thermal stability of RPU/EV/MPP foam at high temperatures was enhanced.

\section{Conclusion}

In this work, the flame retardant and mechanical properties of RPU/EV and RPU/EV/MPP composite foams were studied. It was found that the incorporation of $10 \mathrm{wt} \% \mathrm{EV}$ into rigid polyurethane (RPU) foam (sample PU/EV10) results in $82 \%$ and $115 \%$ enhancement in compressive strength and flexural strength, respectively. Cone calorimeter results show that the peak heat release rate (PHRR) and the total heat release (THR) of RPU/EV15 decrease by $36 \%$ and by $38 \%$, respectively compared with the ones of untreated RPU foam although the LOI of the foam is only $19.5 \%$. A phosphorus- and nitrogen-containing flame retardant, i.e. melamine phenylphosphate (MPP) was synthesized and introduced into the RPU/EV foam. The RPU/EV foam with 15\% MPP (sample RPU/EV/MPP15) can pass the UL-94 V0 test with a LOI of 27.5\%. The PHRR and THR of the sample are further reduced by $39 \%$ and $24 \%$, respectively, compared with the ones of RPU/EV foam without MPP. The thermal conductivity of RPU composite foams in the presence of EV and MPP increases compared with the one of pure RPU foam. The compressive strength and flexural strength of RPU/EV/MPP foam gradually decrease with the increase in the amount of MPP. TGA results indicate that the addition of MPP further increase the residue char of the RPU/EV foam.

Acknowledgement: This work was financially supported by the National Natural Science Foundation of China (21174106).

\section{References}

1. Benjatham S., Duangruthai S., Nuanphun C., Fully water-blown polyisocyanurate-polyurethane foams with improved mechanical properties prepared from aqueous solution of gelling/blowing and trimerization catalysts. e-Polymers, 2019, 19, 277-289.

2. Shi X.X., Yang P., Peng X.F., Huang C.H., Qian Q.Y., Bi-phase fire-resistant polyethylenimine/graphene oxide/melanin coatings using layer by layer assembly technique: Smoke suppression and thermal stability of flexible polyurethane foams. Polymer, 2019, 170, 65-75.

3. da Haro J.C.D., López-Pedrajas D., Pérez Á., Rodríguez J.F., Carmona M., Synthesis of rigid polyurethane foams from phosphorylated biopolyols. Environ. Sci. Pollut. R., 2019, 26(4), 3174-3183.

4. Zhao B., Liu D., Liang W., Li F., Wang J., Liu Y., Bi-phase flameretardant actions of water-blown rigid polyurethane foam containing diethyl-N,N-bis(2-hydroxyethyl) phosphoramide and expandable graphite. J. Anal. Appl. Pyrol., 2017, 124, 247-255.

5. Park H., Keun J., Lee K., Syntheses and physical properties of two-component polyurethane flame-retardant coatings using chlorine-containing modified polyesters. J. Polym. Sci. Pol. Chem., 1996, 34(8), 1455-1464.

6. Zatorski W., Brzozowski Z.K., Kolbrecki A., New developments in chemical modification of fire-safe rigid polyurethane foams. Polym. Degrad. Stabil., 2008, 93(11), 2071-2076.

7. Yuan Y., Yang H., Yu B., Shi Y., Wang W., Song L., et al., Phosphorus and nitrogen-containing polyols: synergistic effect on the thermal property and flame retardancy of rigid polyurethane foam composites. Ind. Eng. Chem. Res., 2016, 55(41), 10813-10822.

8. Modesti M., Lorenzetti A., Flame retardancy of polyisocyanuratepolyurethane foams: use of different charring agents. Polym. Degrad. Stabil., 2002, 78(2), 341-347.

9. Chen M., Shao Z., Wang X., Chen L., Wang Y., Halogen-free flame-retardant flexible polyurethane foam with a novel nitrogenphosphorus flame retardant. Polym. Degrad. Stab., 2012, 51(29), 9769-9776.

10. Shi L., Li Z., Yang M., Yin B., Zhou Q., Tian C., et al., Expandable graphite for halogen-free flame-retardant of high-density rigid polyurethane foams. Polym.-Plast. Technol., 2005, 44(7), 1323-1337.

11. Shi L., Li Z., Xie B., Wang J., Tian C., Yang M., Flame retardancy of different-sized expandable graphite particles for high-density rigid polyurethane foams. Polym. Int., 2010, 55(8), 862-871.

12. Ye L., Meng X., Ji X., Li Z., Tang J., Synthesis and characterization of expandable graphite-poly(methyl methacrylate) composite particles and their application to flame retardation of rigid polyurethane foams. Polym. Degrad. Stabil., 2009, 94(6), 971-979. 
13. Liu L., Wang Z., Xu X., Melamine amino trimethylene phosphate as a novel flame retardant for rigid polyurethane foams with improved flame retardant, mechanical and thermal properties. J. Appl. Polym. Sci., 2017, 134(39), 45234.

14. Liu L., Wang Z., High performance nano-zinc amino-tris(methylenephosphonate) in rigid polyurethane foam with improved mechanical strength, thermal stability and flame retardancy. Polym. Degrad. Stabil., 2018, 154, 62-72.

15. Liu L., Lv R., Synthesis of a DOPO-triazine additive and its flameretardant effect in rigid polyurethane foam. e-Polymers, 2019, 19, 235-243.

16. Sadrmomtazi A., Sobhani J., Mirgozar M.A., Najimi M., Properties of multi-strength grade EPS concrete containing silica fume and rice husk ash. Constr. Build. Mater., 2012, 35, 211-219.

17. Sayadi A.A., Tapia J.V., Neitzert T.R., Clifton G.C., Effects of expanded polystyrene (EPS) particles on fire resistance, thermal conductivity and compressive strength of foamed concrete. Constr. Build. Mater., 2016, 112, 716-724.

18. Johari I., Hamid A., Kasim S.R., Ahmad Z.A., Microstructure and mechanical properties of cement mortar incorporate with coated expanded polystyrene beads. Mater. Sci. Forum, 2017, 888, 234-238.

19. Meng X., Ling Y., Zhang X., Tang P., Tang J., Ji X., et al., Effects of expandable graphite and ammonium polyphosphate on the flame-retardant and mechanical properties of rigid polyurethane foams. J. Appl. Polym. Sci., 114(2), 853-863.

20. Patro T.U., Harikrishnan G., Misra A., Khakhar D.V., Formation and characterization of polyurethane-vermiculite clay nanocomposite foams. Polym. Eng. Sci., 2010, 48(9), 1778-1784.

21. Meng Z., Zhang J., Chen S., Zhou Y., Synthesis and fire properties of rigid polyurethane foams made from a polyol derived from melamine and cardanol. Polym. Degrad. Stab., 2014, 110, 27-34.

22. Rong Y., Bo W., Han X., Ma B., Li J., Synthesis and characterization of flame retardant rigid polyurethane foam based on a reactive flame retardant containing phosphazene and cyclophosphonate. Polym. Degrad. Stab., 2017, 144, 62-69.

23. Chattopadhyay D.K., Webster D.C., Thermal stability and flame retardancy of polyurethanes. Prog. Polym. Sci., 2009, 34(10), 1068-1133.

24. Chen S., Wang B., Kang J., Chen J., Gai J., Yang L., et al., Synergistic effect of organic vermiculite on the flame retardancy and thermal stability of intumescent polypropylene composites. J. Macromol. Sci. B, 2013, 52(9), 1212-1225.

25. Hu X., Wang D., Enhanced fire behavior of rigid polyurethane foam by intumescent flame retardants. J. Appl. Polym. Sci., 2013, 129(1), 238-246.

26. Wu M., Qiao Y., Shang J., Guo Y., Expanded vermiculite applied in the catalytic process as a catalyst support. Appl. Mech. Mater., 2014, 556-562, 335-338.

27. Spirina V.S., Flerova M.I., Expanded vermiculite as heat insulation material. Refractories, 1975, 16(3-4), 201-203.
28. Du X.S., Xiao M., Meng Y.Z., Rajulu A.V., Tjong S.C., Synthesis of poly(arylene disulfide)-vermiculite nanocomposites via in situ ring-opening reaction of cyclic oligomers. Eur. Polym. J., 2003, 39(8), 1735-1739.

29. Liu D., Du X., Meng Y., Facile synthesis of exfoliated polyaniline/ vermiculite nanocomposites. Mater. Lett., 2006, 60(15), 1847-1850.

30. Wang G., Wei X., Influence of caged bicyclic phosphate and $\mathrm{CaCO}_{3}$ nanoparticles onchar-forming property of PU rigid foams. Polym. Degrad. Stabil., 2013, 98(11), 2323-2330.

31. Modesti M., Lorenzetti A., Besco S., Hrelja D., Semenzato S., Bertani R., et al., Synergism between flame retardant and modified layered silicate on thermal stability and fire behaviour of polyurethane nanocomposite foams. Polym. Degrad. Stabil., 2008, 93(12), 2166-2671.

32. Thirumal M., Singha N.K., Khastgir D., Manjunath B.S., Naik Y.P., Halogen-free flame-retardant rigid polyurethane foams: effect of alumina trihydrate and triphenylphosphate on the properties of polyurethane foams. J. Appl. Polym. Sci., 2010, 116(4), 2260-2268.

33. Jiao L., Xiao H., Wang Q., Sun J., Thermal degradation characteristics of rigid polyurethane foam and the volatile products analysis with TG-FTIR-MS. Polym. Degrad. Stabil., 2013, 98(12), 2687-2696.

34. Luo F., Wu K., Guo H., Qiang Z., Liang L., Lu M., Effect of cellulose whisker and ammonium polyphosphate on thermal properties and flammability performance of rigid polyurethane foam. J. Therm. Anal. Calorim., 2015, 122(2), 717-723.

35. Yang H., Wang X., Bin Y.U., Yuan H., Song L., Hu Y., et al., A novel polyurethane prepolymer as toughening agent, Preparation, characterization, and its influence on mechanical and flame retardant properties of phenolic foam. J. Appl. Polym. Sci., 2013, 128(5), 2720-2728.

36. Gao L., Zheng G., Zhou Y., Hu L., Feng G., Xie Y., Synergistic effect of expandable graphite, melamine polyphosphate and layered double hydroxide on improving the fire behavior of rosin-based rigid polyurethane foam. Ind. Crop. Prod., 2013, 50(4), 638-647.

37. Zheng Z., Yan J., Sun H., Cheng Z., Li W., Wang H., et al., Preparation and characterization of microencapsulated ammonium polyphosphate and its synergistic flame-retarded polyurethane rigid foams with expandable graphite. Polym. Int., 2013, 63(1), 84-92.

38. Duquesne S., Bras M.L., Bourbigot S., Delobel R., Vezin H., Camino G., et al., Expandable graphite, a fire retardant additive for polyurethane coatings. Fire Mater., 2010, 27(3), 103-117.

39. Liu L., Wang Z., Facile synthesis of a novel magnesium aminotris-(methylenephosphonate)-reduced graphene oxide hybrid and its high performance in mechanical strength, thermal stability, smoke suppression and flame retardancy in phenolic foam. J. Hazard. Mater., 2018, 357, 89-99. 